\title{
The Reality and Difficulties of Employing ICT in Teaching from the Perspective of Math Teachers of Middle Stage in Riyadh
}

\author{
Mona S. Alghamdi ${ }^{1}$ \\ ${ }^{1}$ College of Education, Princess Nourah bint Abdulrahman University, Saudi Arabia \\ Correspondence: Mona S. Alghamdi, College of Education, Princess Nourah bint Abdulrahman University, \\ Saudi Arabia. E-mail: mtalgamdy@gmail.com
}

\author{
Received: July 27, $2017 \quad$ Accepted: August 30, $2017 \quad$ Online Published: November 28, 2017 \\ doi:10.5539/ies.v10n12p109 URL: https://doi.org/10.5539/ies.v10n12p109
}

\begin{abstract}
The present study aims to identify the reality and difficulties of employing Information Communication Technology (ICT) in teaching from the perspective of female Mathematics teachers of middle stage in Riyadh, Saudi Arabia. The study sample consisted of (165) female Math teachers of middle stage in Riyadh. The tool utilized is a questionnaire; and in order to answer the study questions and verify the validity of its hypotheses, the author used frequencies, arithmetic means, standard deviations, ANOVA, and the Tukey Test. The results showed that the degrees of the availability of most of the domains of using devices and applications in teaching of Math were (often and sometimes). The results also showed that the availability of most of indicators of ICT employment in the teaching of Math for the middle stage was (often), the degree of the difficulties that limit the employment of ICT in the teaching of Math from the perspective of Math teachers was high and medium. The results also showed that there were no statistically significant differences $(\alpha \leq 00.05)$ between the means of responses of the participants due to both scientific qualification and specialization. The results also showed statistically significant differences $(\alpha \leq 00.05)$ between participants' responses due to years of experience. In addition, there were no statistically significant differences $(\alpha \leq 00.05)$ between the means of responses of the participants on each domain of the questionnaire due to years of experience.
\end{abstract}

Keywords: reality, difficulties, ICT, female Math teachers, middle stage

\section{Introduction}

Currently, the human being experiences a large set of changes that form life as a result of the scientific and technological revolution. That is, from the middle of the 20th century, unprecedentedly, scientific and technological developments occurred (Elrawabda, 2002), such as the development of information and communication technology (ICT) (Elzebyani, 2007), known as technology (equipments and software). It is concerned with information's storage, retrieval, circulation, and publishing; and electronically produces oral, visual, text, and digital data via the integration of computers and visual communication systems (Alhamran, 2006; Aljarah \& Elajloni, 2012).

We live in a changing world. The current change is more comprehensive, more effective, and faster than any earlier times. Additionally, it is an introduction to a faster and more comprehensive development and change, especially under the present international challenges of total scientific and technological revolution and the massive development in the means and systems of technology and communication (Fadl \& Elrewy, 2003). They turned the world into a small electronic village where a person can move and identify its items (Murad, 2014) or a global small room indicating the available and ongoing interaction between the parts of the world (Fadl \& Elrewy, 2003).

ICT plays an important role in all aspects of life. It helped create a great cultural leap eliminating any temporal or spatial borders among the members of the community or between the members of a community and those of another one (Murad, 2014).

Over the last years of the 20th century, a massive leap in the innovations of ICT occurred. It greatly affected all aspects of life, including education. Therefore, the experts and policy makers of education across the world were motivated to introduce such innovations in education from kindergarten, illiteracy elimination and elderly education, special education, to university education and beyond. The innovations and products of ICT helped 
create an interactive educational environment that is rich in the distinctive activities that magnificently support the educational process. They also shifted education to various virtual worlds to open different horizons around the learner, enabling him/her to increase knowledge and skills endlessly (Bakhiet \& Alhasan, 2013).

From the beginning of the century, the world witnessed a massive cultural movement that covered all aspects and fields of life. That is, everyday new inputs that require new experience, intellect, and skills to be handled successfully appear. Such transformations are reflected in the educational system. Therefore, performing the multiple functions required of education depends on the competence of those in charge of it. However, the scientific and technological progress takes part in facilitating education learning; providing and fostering economy; creating tools, equipment, and programs; introducing educational philosophies, theories, and attitudes, the quality and competence of education cannot be accomplished but with the competent teacher who can successfully and effectively play the assigned roles (Olimat, 2014).

Education lies in the heart of social systems in modern societies that were interested in and keen on benefiting from progress movements to meet their educational and developmental needs. According to Lal (cited in Elzebyani, 2007), "the information and technique became of the most important key needs of the educational process. In addition, Abudaly (cited in Elzebyani, 2007) argues that "the critical contemporary changes in ICT imposed completely new horizons on the educational process and required fast training to keep pace with the age and its changes".

ICT concept was broadened via three components, i.e. the computer, communication networks, and customer's electronics that are used to meet people's needs including TV, disk recorders, stereo and sound devices...etc. To conclude, information technology covers all developed technologies used to transform data, in its various forms, to the various forms of information exploited by users in all life aspects (Elsalamey, 2002).

It is noted that the speed progress in ICT and education technology shows an integration between the fields occurred that caused the emergence of new horizons represented by technological innovations that are directly related to the educational process, e.g. e-learning. This requires qualified teachers who are trained to handle and adopt in education and can perform new roles and functions that match its requirements (Olimat, 2014)

Modern technology provided means and tools that played a great role in developing the recent methods of education and learning. They also allowed improving them to create the effective educational atmosphere to draw the attention and motivate students to face their individual differences effectively. Due to the expansion of the technological innovation, the computer was invented representing a quality shift and a challenge to all former innovations and tools. Educational scientists also searched and experimented to identify the potential educational abilities in the multiple computer abilities. Clearly, the computer becomes the topic, tool, and means of education. It can also play the role of the teacher and discusses the students to help him/her acquire key life skills (Alqurashy, 2007).

That is, in the age of science and modern technology, the computer is a manifestation of progress. In addition, its language is the language of the age that represents the 4th key skill besides reading, writing, and arithmetics. Being ignorant of it is the feature of illiteracy in the near future (Alqurashy, 2007).

Hence, we cannot deny that we live in the world of technology because it quickly changes life. Now, it is impossible to ignore the dissemination of information technology in education as it is a valuable source to educators (Ayas, 2006). Therefore, governments largely invested this area (Albaqaly, 2011; Bebell, Russell, \& O’Dwyer, 2004).

With the technological explosion outside schools, it cannot be expected that schools can be the center of pioneering in helping students master it (Casey, 2008). However, studies revealed that this step has a very limited role in improving the educational outcomes of most students because of the lack of employing such equipment and programs in a way that enable accomplishing the desired educational objectives (Cuban, Kirkpatrick, \& Peck ,2001 cited in Albaqaly, 2011).

Undoubtedly, employing ICT in teaching is the focus of all fields including Math that has a special importance to be at the heart of interest of many countries, especially the advanced ones as they seek the development of teaching methods because of their effective role in the development and progress of communities and being a prerequisite of scientific competition and progress. Therefore, teaching Math should motivate learners' thinking and help them discover and grasp information to play an effective role in the teaching and learning of Math. Accordingly, it is the responsibility of Math teachers to promote its level of teaching and accomplish the desired results. This requires doubling their efforts and exploiting their capabilities and abilities. They cannot do this without the development and diversity of teaching methods (Elzahrany, 2005). 
Many international organizations, e.g. the National Council of Accreditation for Teacher Education (NCATE) and the International Society for Technology in Education (ISTE) set standards related to educational technology and their performance indicators to teachers that should be adopted in their preparation programs (Olimat, 2014). They are facilitating and motivating students' learning and creativity, designing and developing learning and evaluation practices that keep up with the digital age, providing a model for work and education in the digital age, motivating and introducing citizenship and digital responsibility sample, and contribution to development and professional progress (Arab Bureau of Education for the Gulf States, n.d.).

It is worth mentioning that the role of ICT was introduced to the educational process from the mid20th century. They help teachers plan and prepare lessons to be offered to students in an attractive and effective way (Leach cited in Jamiu, 2016). They also help students pursue effective learning(Sutton cited in (Elnaeby, 2010).

With the increased interest in avoiding the stereotypes of teaching in the classroom, it is noted that ICT began to play an effective role in reorganizing the classroom educational situation concerning the planning, designing, and implementing classroom activities, classroom interaction, guidance, advising, evaluation, and assessment through the communications, information, and methods of display in the various stages; they are an important source of knowledge (Forsyth, 1998; wan, 2000; Kelch \& Karr-Kidwell, 2000 cited in A. Elomary \& K. Elomary, 2008). This changes the role of teacher in the administration of the classroom educational situation, imposing the development of the various skills and abilities (A. Elomary \& K. Elomary, 2008).

According to the head of educational technology office in USA (2001), the modern educational studies and research aimed at the positive impact of employing the technologies in general to achieve the objectives of education (Ismael, 2003).

In 1996, the American Minister of Education announced the first national plan of educational technology that aim to qualify the American students to face the 21 st century. It covered an effective usage of technology in schools for a better educational preparation to respond to the requirements of the labor market. In 1999, there was a critical revision of this national plan. Statistics indicated that the American government implemented it. In 2000, USA spent about (2.2) billion dollars on e-trainings. In 2007, It reached 11.4 billion dollars. It is worth noting that $60 \%$ of this amount of money is dedicated for e-learning (Salem cited in Elzebyani, 2007).

Because Saudi Arabia believes in the importance of information and the role it plays in community development, it supported the attitude of governmental bodies to have the systems of information and training with big budgets. In its concurrent developmental plans, covered items that require the use of computers in the governmental bodies and training on them to upgrade their competence and develop the national human resources to bridge the gabs of the requirements of these plans (Elhemealy, 2005).

Despite the global and local interest in using ICT in teaching Math and its positive role in the improvement of students' achievement, international studies, e.g. TIMSS-2015, reported the low level of Saudi students in Math due to the traditional teaching methods adopted by the teacher. Therefore, the problem of the current study was defined in identifying the reality and difficulties of employing ICT in teaching Math from the perspective of female teachers.

\section{Theoretical Framework}

\subsection{Stages of ICT:}

Shetat (cited in Elomary \& Anaqra, 2011) reported (4) stages of ICT regarding its effect on e-learning. The first stage (before 1983) was referred to as the age of traditional teacher when education was traditional before the spread of computers although some people had them and they were limited to DOS software and using magnetic discs. The communication between the teacher and student was happening in the classroom according to a certain schedule. The second one from 1984 to 1993) was known as the age of video disc and multimedia. It was characterized with interface operating systems, e.g. Windows and Mac and CDs were used as key tools of education development. The third stage (from1993 to 2000) began with the emergence of the Internet and Intranet, e-mail for discussion and video conference, and e-programs to display video moves. Multimedia witnessed a massive development besides the emergence of learning management systems (LMS). The fourth one (from 2001) represented the second generation of the World Wide Web when web design was more advanced with stronger features regarding speed and the condense of content. In addition, learning content and management systems (LCMS), VLE, and wireless connectivity were introduced.

\subsection{Approaches of Employing and Using ICT by the Educational Institutions}

Daniel (2002) reports four approaches followed by the educational institutions in employing and using ICT, as follows: 
1) Emerging approach is demonstrated by schools at the beginning stages of ICT development by having computer devices and software via purchase or donation. At that time, teachers explore the potentials and consequences of using ICT for school management and adding ICT to the activities of the curriculum.

2) The applying approach is demonstrated when teachers and administrators use ICT for assignments implemented in school management and the curriculum. In this stage, schools increase the use of ICT in various subjects with specific tools and software.

3) The infusing approach involves the integration or embedding ICT across the curriculum. Schools employ a set of computer-based technologies in laboratories, classrooms, and administrative offices. Teachers investigate new ways of dealing with ICT to develop their professional roles and increase their practical and professional experience.

4) The transforming approach takes place when schools that use ICT reorganize and renew schools in creative ways. Thus, ICT becomes a part of the daily production activity and professional practice. The focus of the curriculum is learner-centred and the subjects are integrated in the real-world and its applications. ICT is taught as a separate project in the vocational preparation of the teacher.

\subsection{Applications of ICT in the Educational Field}

Jacobson (cited in Alqurashy, 2007) reported various forms of technology that could be employed in education. Teachers argued that they are completely aware that using technology helps educate students. After conducting some studies to monitor the reality of using technology, he reported that using ICT is increasingly used in schools. Thus, he concluded that:

- Technology is less employed in humanities than physics and math.

- Using e-mail in the search and communication helps save students' time.

- Most students spend more time in learning the computer than that of learning its content.

- Most university instructors do not like to allocate the adequate time of using technology in the classroom.

- There are various computer applications in education.

\subsection{Hypotheses Related to the Learning Model Using ICT Tools}

Rakes (1996) and Dibs (1983) (cited in Hamdy, 1998) reported a set of hypotheses related to the technological model of learning. They, as reported by Alhamran (2006), undoubtedly apply to the learning model that uses ICT tools. They are:

1) Knowledge is not the truth. It is implied in their appropriateness to the student and his/her needs. Thus, $s /$ he can organize information on his/her own using skills and experience.

2) The student is the focus of the practical educational process. His/her needs is the basis of education and collecting information.

3) Allowing the student to select and apply the skills to help search and face problems. Students are an active and research group.

4) Students acquire the truth of information availability in various forms, including books, periodicals, movies, slides, software...etc.

5) Learners conclude knowledge on their own. This model focuses on the mechanism of acquiring knowledge.

6) The student is evaluated according to the acquired knowledge and observing progress in the set objectives.

\subsection{Importance and Advantages of Using a Tool of ICT (The Computer) In Education}

Najy (2001) argued that the experience of many countries showed that using the computer in education helps a lot by:

1) Achieving positive participation of the learner and developing his sense and ability to make decisions and fostering the continuity and attitude towards the productive learning.

2) Teaching learners more vitality and interaction with the computer to consolidate research, creativity, taking care of the gifted capabilities and readiness, and motivating low-achievers to avoid their weakness.

3) Promoting the type of the educational process by training learners to think and reflect while learning and motivate them to discover, induct, and conclude to sharpen their skills, knowledge, and experience.

4) Condense learners' information and motivate them to retrieve it via controlling the educational situation on 
the computer.

5) Fostering learning motivation among learners to enable them to visualize the results of their learning and progress towards the learning objectives instantly and positively as mistakes are corrected according to understanding and comprehension.

6) The ability of the computer to display experiments, simulation programs, and purposeful games as a tool of investigation and artistic creativity.

7) Consolidating the educational work by offering a tool to the learner to help induct new educational methods that use the scientific and technological innovations to improve the educational outcome.

8) The computer has various facilities to achieve the strategy of education proficiency. It benefits from the educational programs in the display, interaction, and revealing.

9) The computer is characterized, rather than the audio-visual devices, by displaying the alphabetical and digital information and drawings.

10) It interacts with the learner to enable him/her to respond and consolidate this response to pursue learning to unite education and evaluation and education and games.

11) International researches showed the effectiveness and role of the computer in improving education if added to the traditional education.

12) Fear, terror, and shyness are eradicated from the learner who overcomes individual differences.

13) Inserting the computer in the various programs of education saves the learner's staying at the level of the community by preparing the Arab human being with the ability to interact with this modern technology.

14) It provides instant feedback along with instant consolidation because positivism fosters learning and negativity corrects it.

15) It abbreviates the time of learning and education that corresponds the speed of self-learning.

16) It saves effort, money, and time by simulating real experience and exercises.

\subsection{Models of Professional Development in ICT}

Watson (cited in Alhamran, 2006) discussed four models of professional development in ICT. They were:

1) In this model, the teacher of professional development is a teacher and a trainer who experienced the process. He is thought to come from an environment that is rich in experience and skills. Thus, he is more open to training.

2) In this model, the trainer explains and illustrates the methods. Then, he closely monitors teachers and provides assistance, if needed.

3) The trainer stops being the person who provides all answers in the room as the source of facts and information. Trainers produce experience themselves. In addition, each trainer experiences the activity and interacts with all capabilities to prove himself and his abilities.

4) This model depends on the attractiveness of the good resources of ICT to create the motivation and interest of the learners. The availability of a strong infrastructure should be assured along with all the human and material capabilities required to employ ICT.

\subsection{The Stages Followed by the Teachers and Students to Achieve Trust by Using ICT}

Studies related to school learning and education across the world reports four stages to be followed by teachers and students to achieve trust using ICT (Daniel, 2002), as follows:

1) Discovering ICT tools; it involves discovering ICT tools along with their purposes and uses by teachers.

2) Learning how to use ICT tools; it covers learning how to use ICT tools and starting using them in the various fields.

3) Understanding how and when to use ICT tools; in this stage, there is a complete understanding of the mechanism of use and defining the appropriate and required conditions besides the adequate time to use each tool to accomplish the aspired objectives.

4) Specializing in the use of ICT tools; it covers specializing in the use of ICT tools such as what happens when a person in specialized in ICT science. The learner embarks on ICT as a specialized topic. It covers the skills and professional and specialized competences, not the general ones. 


\section{Review of Literature}

Elzahrany (2005) investigated the reality of using the computer and Internet in teaching Math to the secondary stage regarding usage, obstacles and attitudes. The study applied a questionnaire to (158) teachers and (15) educational supervisors. It concluded that using the computer in office work related to teaching Math was generally medium. However, its use as an educational tool in all fields was largely small. Using the Internet and benefiting from its services in teaching Math was generally medium. Its obstacles were lack of training on using its services, lack of adequate time, low level of English, and weak network. Furthermore, there were no statistically significant differences between the two groups of teachers and supervisors towards all domains.

Khazaleh and Jawarneh (2006) explored the perceptions and perspectives of a group of in-service teachers to define the barriers to the effective integration of information technology in Jordanian schools. After giving interviews to (61) teachers in basic and secondary schools, data were analyzed. The study concluded that there were (6) categories of barriers: a severe shortage of computers and related equipment, lack of adequate teacher training programs, inadequate basic skills of students, insufficient time for teachers for the preparation of curricular integration, few access to the available computers in schools, and rarity of good locally produced instructional software.

Tella et al. (2007) investigated the use and implications of Nigerian secondary school teachers of ICT. The study was applied to 700 teachers from 25 purposefully selected private secondary schools in Ibadan, Nigeria; 430 males and 270 females, aged (25-45), with a mean age of 35 years. It concluded that ICT was generally accessed except e-mail and Internet because the schools were not connected. Technical support was inadequate and teachers were inexperienced. Furthermore, teachers perceived ICT as being easier and very useful in teaching and learning. To be continually used, it was recommended that teacher training and professional development oriented policies should support ICT-related teaching models that motivate the students and teachers to play active roles in teaching/learning activities. Elzebyani (2007) explored the reality of using contemporary technology in teaching Math to the middle stage from the perspective of teachers in Yanbu. The study applied a questionnaire to 62 Math teachers of the middle stage. It illustrated that modern technology was rarely available in the middle schools. In addition, its use was also very low. However, the difficulties perceived by teachers were high. There were no statistically significant differences in the population's responses that could be attributed to qualification, training, or years in service. Alqurashy (2007) investigated the reality of using the computer, World Wide Web and Internet in teaching Math to the first middle grade. The study applied a questionnaire to a sample of 159 Math teachers. It concluded that there were unavailable projectors, inappropriate place, rarity of training, and unavailable instruction materials in Arabic. There were statistically significant differences in using the Internet in Math teaching in favor of the private schools. Additionally, there were statistically significant differences in using the computer as an educational means that could be attributed to qualification and years of experience. Furthermore, there were statistically significant differences between the teachers in public and private education towards using the computer and the Internet in teaching favoring private education teachers.

Dakich, Vale, Thalathoti, and Cherednichenko (2008) introduced a paper that presented the findings of a survey that examined factors influencing teachers' ICT literacy. Dakich et al. (2008) surveyed the factors that influence teachers' ICT literacy. The study surveyed (350) teachers in the government primary schools in Australia utilizing a framework of ICT literacy to explore the factors that influence the development of the skills and knowledge of teachers. It concluded that the factors that influenced the development of ICT literacy included age, gender, teaching experience, and teachers' use of computers. Elomary and Elomary (2008) aimed to identify the reality and obstacles of using ICT in the classroom educational situation's skills in the first three grades from teachers' perspective. The study applied a questionnaire to a sample of 310 teachers; 136 males and 174 females. It illustrated that 31 out of 55 schools used ICT. While $26 \%$ of the teachers used the computer and the Internet in teaching planning, $21 \%$ used it for evaluation, and $15 \%$ used it for teaching implementation. They achieved low percentages in tests and classroom management of $5 \%$ and $2 \%$, respectively and personal use achieved $21 \%$. The most significant obstacles revealed were dissatisfaction of the principals of change and inappropriateness of classroom environment for applying ICT. Bate (2010) investigated the findings of a longitudinal study that examined the way 35 teachers employed ICT in their first three years of their teaching The study mixed approaches to help understand the role played by ICT in the evolving pedagogical practices. It concluded that the teachers under study articulated pedagogical beliefs to engage their students in active meaning making. In addition, they were competent in the use of a basic suite of ICT software. They did not use ICT in ways that matched their stated pedagogical beliefs. The study presented a framework to assure that teachers and school leaders need to make connections across pedagogical and technological domains. Tezci (2011) identified the perceptions of the Turkish primary school teachers of school culture regarding ICT integration in education and 
the factors that might influence them. The study covered 1540 primary school teachers. It concluded that the teachers' perceptions in both motivational and technical aspects were not positive. These perceptions were affected by gender, ownership of a personal computer, Internet access, professional experience, and weekly computer use.

Albaqaly (2011) investigated the reality of using ICT in the classroom teaching in Bahrain. The study applied a questionnaire to 812 teachers of the various stages of the public stages; 334 males and 478 females. Results revealed that the mean of using ICT in planning and display was good, while it was medium in evaluation. They also revealed that gender had no statistically significant differences on the use of ICT in classroom teaching.

Buabeng-Andoh (2012) explored the global investment in ICT to improve teaching and learning in schools. The study reviewed personal, institutional, and technological factors to motivate teachers' use of computer technology in teaching and learning processes. It examined the obstacles of using including lack of ICT skills, lack of confidence, lack of pedagogical training, lack of suitable educational software, limited access to ICT, rigid structure of traditional education systems, restrictive curricula...etc. It concluded that defining how these obstacles affect individuals and institutions can help make decisions to tackle them.

Hismanoglu (2012) investigated the perceptions of EFL teachers in the distance higher education system towards ICT implementation in EFL teaching. The participants mainly expressed negative attitudes to ICT integration regarding the nature, level, and delivery of the training. Accordingly, they affirmed that they were competent enough to use ICT in the future subject teaching without the adequate knowledge of ICT. Results showed that training is critically required to enable teachers to become competent in and receptive to ICT. Narinasamy and Mamat (2013) discussed the need to incorporate ICT in moral education. The study adopted the qualitative approach using non-participant observation, semi-structured interviews and teachers' journals to identify their employment of ICT in teaching. It highlighted the lack of ICT utilization in teaching moral education indicating that their training was deemed vital to make teachers and school authorities aware that ICT is a a significant pedagogical tool in creating a positive learning environment.

Bakhiet and Alhasan (2013) investigated the reality of ICT in the schools of the gifted. The study applied a questionnaire to (56) teachers; (29) males and (27) females. It concluded that there were few ICT equipment and programs in the schools. In addition, there was no correlation between the degree of using and age, experience, and training courses in the field. There were also no statistically significant differences between teachers according to academic qualifications, specializations, and gender in ICT. However, there was a direct correlation between the availability and use of ICT. Alqahtany (2013) evaluated the reality of using technological innovations by Math teachers in teaching the developed curricula from the perspectives of teachers and supervisors. The study applied a questionnaire to (62) Math teachers and (13) educational supervisors. Results showed the shortage of Math teachers in supporting the educational environment in the class with technological innovations to motivate learners to positively interact. There was also a shortage in their adoption in planning, teaching implementation, and evaluating learners' performance. They were adopted in the self-development of Math teachers. Furthermore, there were statistically significant differences between the means of the groups' opinions that could be attributed to academic qualification and teaching experience. There were not statistically significant differences that could be attributed to the nature of the profession (teacher-supervisor).

Copriad (2014) examined teachers' motivation to employing ICT in their teaching and learning. The study also differentiated the influence of exsogenous and endogenous variables according to the academic fields (pure science and social science). It applied a survey to (874) high school teachers in Indonesia; (446) science teachers and (428) social science teachers. It illustrated that motivation was significant as a mediator between readiness with ICT application in teaching and learning science and social science. It recommended that the governments and Ministry of Educations should consider teachers' attitudes and motivations in applying ICT by providing them with sufficient infrastructure, equipments, facilities, and training to develop positive attitudes towards ICT in education.

Murad (2014) explored the knowledge, use, and obstacles of the basic ICT applications and software of a sample of teachers in Shoubak educational directorate. The study applied a questionnaire to a sample of (101) teachers; (42) males and (59) females. It showed that most of the sample appropriately practiced the various software and applications of ICT but their use for teaching purposes was low. The most significant obstacles of ICT were the unavailability of the required equipment and infrastructure; some of them were related to the weak training on using ICT in teaching. Olimat (2014) investigated the use of technological innovations by Science teachers in Mafraq governorate. The study applied an observation tool of 46 items that covered 6 domains to 108 teachers. It concluded that the use of technological innovations was medium. In addition, there were statistically significant 
differences in their use that could be attributed to experience in multimedia programs and (5-10) years of experience. There was also a statistically significant interaction between the teacher's experience and gender in projector device and multimedia programs. Gebremedhin and Fenta (2015) investigated teachers' perceptions, usage, and obstacles of ICT integration in the teaching-learning process. The study covered (72) teachers at Adwa College. It revealed that the teachers could not use hardware in teaching-learning process due to the shortage of resources. Thus, they did not integrate ICT in the course taught. Moreover, they had a strong positive perception to use ICT in teaching-learning process. There was also a significant relationship between their perception of ICT integration into teaching-learning process and the factors motivating ICT usage. However, they mainly reported that the lack of technical knowledge and shortage of resources hindered them. Therefore, the study recommended that the College should critically focus on integrating ICT in each course to make them interactive and easily understandable.

Alrajeh and Elzain (2015) investigated the reality of the digital technology in supporting the professional development of female Math teachers. The study applied a questionnaire to (294) female teachers. It illustrated that the benefit from the forums and websites of Math education, e.g. Yazeed educational forums and Math educational network, was high. They were followed by social media represented by Youtube and the programs of mathematical writing and text processing represented by processing the texts of writhing mathematical symbols. The digital technology that was ranked last in supporting the professional development of the female Math teacher was digital news media including the digital newspapers and journals. All the fields of benefiting from digital technology in Math teaching obtained a medium degree. Planning was ranked first. It was followed by female students' learning, teaching, cognitive development, evaluation, and content development, respectively. In addition, there were statistically significant differences between the means of benefiting from digital technology in Math education between secondary and primary schools' female teachers in favor of those of the secondary stage. There were no statistically significant differences between the means of benefiting from digital technology in Math education that could be attributed to years of experience.

Konca et al. (2016) determined the attitudes of preschool teachers towards using some technological tools and analyzed it in terms of different variables. The study applied a personal information form to (103) kindergarten teachers in Kirsehir and Malatya in the fall semester of 2014-2015. The participants showed a positive attitude towards using technological tools. Preschool teachers showed a more positive attitude towards using technological tools than the distance education graduate preschool teachers.

Bindu (2017) explored the awareness of and attitude towards using ICT in teaching by the Indian teachers in UAE according to their gender and age. A questionnaire and interview were employed to collect data from (57) teachers from (7) Indian curriculum schools. The study illustrated that teachers had a positive attitude towards using ICT regardless of their gender and age. However, their ICT awareness was medium and was affected by gender and age. Therefore, it recommended that ICT use for educational purposes should be given greater consideration than it currently receives.

\section{Statement of the Problem and Questions of the Study}

Undoubtedly, there is a great challenge in using educational technology in the educational process. It was motivated by the changing role of the school and teacher in the age of technology. Thus, focus shifted to give the student the opportunity to participate in the educational process and to have self-reliance to identify the technological means and communication and how to use them in learning and education. In addition, thee was a focus on providing the student with the skills of self-search and obtaining the information using the computer and the Internet to work effectively to meet the requirements of the age (Naddaf, 2002). Math, as a significant key field, was affected by the community changes of all their aspects besides new scientific aspects that were related to using technological devices and programs and modern means (Alqahtany, 2013). Thus, the educational institutions should define the reality of employing ICT in teaching Math. In addition, the reality of its employment was also investigated to accomplish interaction between the educational process and teachers because the teacher is the core of the educational process due to the ability to plan, design, and ultimately use all the available features in favor of the educational process (Alqahtany, 2013).

Literature revealed that the local studies in the field are rare. Therefore, the current study was conducted to bridge a gap and to participate to develop the performance of Math female teachers in the field of employing ICT in Math teaching. Accordingly, the study attempts to answer the following major question "what are the reality and difficulties of employing ICT in teaching from the perspective of female Math teachers of middle stage in Riyadh?". It is, further, sub-divided into the following minor questions:

1) To what extent devices and applications are used in teaching Math from the perspective of female Math 
teachers of middle stage?

2) To what extent ICT is employed in teaching Math from the perspective of female Math teachers of middle stage?

3) What are the difficulties of employing ICT in teaching Math from the perspective of female Math teachers of middle stage?

\section{Hypotheses}

1) There were no statistically significant differences at the level of $(\alpha \leq 00.05)$ between the means of responses of the participants due to scientific qualification.

2) There were no statistically significant differences at the level of $(\alpha \leq 00.05)$ between the means of responses of the participants due to specialization.

3) There were no statistically significant differences at the level of $(\alpha \leq 00.05)$ between the means of responses of the participants due to years of experience.

\section{Significance}

1) It tackles the principle of technology which is one of the six principles set by the National Council of the Teachers of Math (NCTM) because it plays a significant role in educating and learning math. It affects Math that is being taught and supports students (Abuzaina and Ababna, 2007).

2) It tackles a new approach in the educational process, i.e. e-learning in an appropriate way.

3) It is a procedural response to the perception of reality that match the quickness of contemporary educational technology and using it in teaching as group or individual tools in teaching that reflect the best use of ICT to support students' learning (Olimat, 2014).

4) The research provides a tool that can be employed to measure the use of ICT in classroom teaching by teachers.

5) The results of the study may provide decision makers with a clear vision of the reality of employing ICT in teaching. Accordingly, they form a real informational database that contributes to making decisions on developing the employment of ICT in teaching (Elomary and Elomary, 2008).

6) It may help develop the programs of Math teachers' preparation to match the employment of ICT in their future teaching.

7) The results may contribute to preparing training programs to in-service female Math teachers in the employment of ICT in Math teaching.

8) The results may help Math curricula planners replan the current curricula in the light of the employment of ICT.

9) The results may help define the most significant difficulties that hinder the employment of ICT in Math teaching to make the appropriate decisions to overcome them.

10) It was based on the rarity of studies and scientific research in Saudi Arabia in the field of evaluating the employment of ICT in Math teaching by the female teachers.

\section{Limitations}

Objective limitations: The study was limited to:

1) The extent devices and applications are used in teaching Math from the perspective of female Math teachers.

2) The extent ICT is employed in teaching Math from the perspective of female Math teachers.

3) The difficulties of employing ICT in teaching Math from the perspective of female Math teachers.

Temporal limitations: The study was applied in the second semester of 2016/2017.

Spatial limitations: The public middle schools in Riyadh.

Human limitations: A sample of the public female Math teachers of middle stage.

\section{Tool of the Study}

A tool was utilized according to the following procedures:

1) Setting the objective: 
The following studies were used in creating the tool of the study Elzebyani (2007), A. Elomary and K. Elomary (2008), Albaqaly (2011), Alqahtany (2013), Murad (2014), Olimat (2014), and Alrajeh and Elzain (2015).

2) Designing the questionnaire in its preliminary form of (62) items on (3) domains, as follows:

a) Devices and applications used by the female Math teachers of middle stage; of (18) items.

b) Indicators of employing ICT by the female Math teachers of middle stage; of (29) items.

c) Difficulties that hinder employing ICT by the female Math teachers of middle stage; of (15) items.

3) The questionnaire was reviewed by (5) reviewers (full professor, associate professor, and assistant professor) to verify its validity to give their opinions regarding (the scale of each domain, clarity of formatting, and the items included in each domain). Some modifications were made including deletions and insertions. In it final form, the questionnaire comprised (59) items on the previous three domains, as follows:

a) Domain I comprises 14 statements.

b) Domain II comprises 30 statements.

c) Domain III comprises 15 statements.

4) The questionnaire was electronically designed via Google.

5) It was applied to a pilot sample of (30) female teachers. Then, the internal validity coefficient of each item was calculated by calculating the correlation coefficient of each item. Items with a correlation coefficient less than 0.3 were deleted; they were 7 . Accordingly, in its final form it comprised 52 items on the former thhree domains, as follows:

a) Domain I comprises 10 statements.

b) Domain II comprises 30 statements.

c) Domain III comprises 12 statements.

6) Internal validity of the domains was calculated by estimating the correlation coefficient of the total mark of the domain to that of the questionnaire, as shown in Table 1.

Table 1. Internal validity

\begin{tabular}{lc}
\hline Domain & Correlation coefficient \\
\hline Domain I & $.750^{* *}$ \\
Domain II: & $.953^{* *}$ \\
Domain III: & $.628^{* *}$ \\
\hline
\end{tabular}

7) Reliability coefficient of the questionnaire and its domains was calculated by calculating Cronbach's alpha, as shown in Table 2.

Table 2. Reliability coefficient of the questionnaire and its domains

\begin{tabular}{lcc}
\hline Domain & No. of items & Cronbach's alpha coefficient \\
\hline Total & 52 & .956 \\
Domain I & 10 & .860 \\
Domain II: & 30 & .948 \\
Domain III: & 12 & .939 \\
\hline
\end{tabular}

\section{Variables}

9.1 Independent Variables

- Qualification

- Specialization

- Years of experience

\subsection{Dependent Variables}

- The extent to which devices and applications are used in teaching Math from the perspective of female Math teachers. 
- The extent ICT is employed in teaching Math from the perspective of female Math teachers.

- The difficulties of employing ICT in teaching Math from the perspective of female Math teachers.

\section{Methodology}

The study adopted the descriptive approach as it suits its nature and objectives. It is based on investigating the reality or the phenomenon. It accurately describes it and qualitatively or quantitatively expresses it. While the qualitative approach describes and clarifies the phenomenon, the quantitative approach describes its quantity, size, or correlation with other phenomena (Obidat et al., 1984).

\subsection{Population}

The population comprised all female Math teachers of middle stage in the public schools in Riyadh in the scholastic year 2016/2017 numbered 960 teachers.

\subsection{Sample}

Table 3. Distribution of the sample according to qualification, specialization, and years of experience

\begin{tabular}{cccc}
\hline Category & Sub-category & Frequency & Percentage \\
\hline \multirow{4}{*}{ Qualification } & General secondary stage & 1 & .6 \\
& Diploma & 3 & 1.8 \\
& Bachelor & 148 & 89.7 \\
& Higher Diploma & 3 & 1.8 \\
& Master & 9 & 5.5 \\
Specialization & Ph.D. & 1 & .6 \\
& Math & 152 & 92.1 \\
& Other & 9 & 5.5 \\
& Less than 5 years & 4 & 2.4 \\
& From 5 to 10 years & 45 & 9.1 \\
Years of experience & From 10 to 15 years & 25 & 15.3 \\
& From 15 to 20 years & 56 & 33.9 \\
& More than 20 years & 24 & 14.5 \\
\hline & Total & 165 & 100.0 \\
\hline
\end{tabular}

\subsection{Applying the Tool of the Study}

The questionnaire was applied to the sample of female Math teachers of middle stage. Data were statistically analyzed via SPSS utilizing frequencies, arithmetic means, standard deviations, ANOVA, and the Tukey test.

To facilitate the interpretation of results, the following approach was employed to define the level of response to the reality of employing ICT in teaching from the perspective of female Math teachers of middle stage in the tool of the study. Alternatives were measured, as follows: (always) $=5 ;($ often $)=4 ;($ Sometimes $)=3$; (rarely) $=2$; $($ never $)=1$. Then, responses were classified into five equal levels using the following formula (Eljahemy, 2010), as shown in Table 4.

Length of the category $=$ (greatest value- least value $) \div$ number of alternatives $=(5-1) \div 5=0.8$.

Table 4. Distribution of categories according to the scale used in the reality of employing ICT in teaching from the perspective of female Math teachers of middle stage in the study tool

\begin{tabular}{lccc}
\hline Description: & Range of means & Description: & Range of means \\
\hline Always & $4.21-5$ & Rarely & $1.81-2.60$ \\
Often & $3.41-4.20$ & Never & $1-1.80$ \\
Sometimes & $2.61-3.40$ & & \\
\hline
\end{tabular}


The following approach was employed to define the level of response to the obstacles of employing ICT in teaching from the perspective of female Math teachers of middle stage in the tool of the study. Alternatives were measured, as follows: $($ great difficulty $)=1 ;($ medium difficulty $)=2 ;($ slight difficulty $)=3$; $($ no difficulty $)=4$. Then, responses were classified into five equal levels using the following formula (Eljahemy, 2010), as shown in Table 5.

Length of the category $=$ (greatest value- least value $) \div$ number of alternatives $=(4-1) \div 4=0.75$.

Table 5. Distribution of categories according to the scale used in the difficulties of employing ICT in teaching from the perspective of female Math teachers of middle stage in the study tool

\begin{tabular}{lccc}
\hline Description & Range of means & Description & Range of means \\
\hline Great difficulty & $1-1.75$ & Slight difficulty & $2.51-3.25$ \\
Medium difficulty & $1.76-2.50$ & No difficulty & $3.26-4$ \\
\hline
\end{tabular}

\section{Results}

Answering research questions:

To answer the first question "to what extent devices and applications are used in teaching Math from the perspective of female Math teachers of middle stage?" frequencies, percentage, and arithmetic means are used, as shown in Table 6.

Table 6. Frequencies, percentage, and arithmetic mean of the participants' responses to "devices and applications used by the female teachers in teaching Math to the middle stage" domain

\begin{tabular}{|c|c|c|c|c|c|c|c|c|c|c|c|c|}
\hline \multirow{2}{*}{ No. } & \multirow{2}{*}{ Item } & \multicolumn{2}{|c|}{ Always } & \multicolumn{2}{|c|}{ Often } & \multicolumn{2}{|c|}{ Sometimes } & \multicolumn{2}{|c|}{ Rarely } & \multicolumn{2}{|c|}{ Never } & \multirow{2}{*}{$\begin{array}{l}\text { Arithmetic } \\
\text { mean }\end{array}$} \\
\hline & & $\mathrm{T}$ & $\%$ & $\mathrm{~T}$ & $\%$ & $\mathrm{~T}$ & $\%$ & $\mathrm{~T}$ & $\%$ & $\mathrm{~T}$ & $\%$ & \\
\hline 1 & E- Educational Games & 6 & 3.6 & 19 & 11.5 & 76 & 46.1 & 30 & 18.2 & 34 & 20.6 & 2.07 \\
\hline 2 & $\begin{array}{l}\text { Software of teaching Math (e.g. GeoGebra, } \\
\text { Sketchpad, and Graphing Calculator). }\end{array}$ & 7 & 4.2 & 32 & 19.4 & 63 & 38.2 & 24 & 14.5 & 39 & 23.6 & 2.66 \\
\hline 3 & Social Media, e.g. Twitter and Facebook & 19 & 11.5 & 24 & 14.5 & 54 & 32.7 & 33 & 20.0 & 35 & 21.2 & 2.75 \\
\hline 4 & Photo Editor and Video Maker & 23 & 13.9 & 29 & 17.6 & 62 & 37.6 & 20 & 12.1 & 31 & 18.8 & 2.96 \\
\hline 5 & YouTube & 46 & 27.9 & 43 & 26.1 & 48 & 29.1 & 17 & 10.3 & 11 & 6.7 & 3.58 \\
\hline 6 & Excel & 20 & 12.1 & 31 & 18.8 & 63 & 38.2 & 25 & 15.2 & 26 & 15.8 & 2.96 \\
\hline 7 & Access & 8 & 4.8 & 20 & 12.1 & 50 & 30.3 & 32 & 19.4 & 55 & 33.3 & 2.36 \\
\hline 8 & Educational Sites & 80 & 48.5 & 44 & 26.7 & 25 & 15.2 & 5 & 3.0 & 11 & 6.7 & 4.07 \\
\hline 9 & E-Forums & 59 & 35.8 & 38 & 23.0 & 38 & 23.0 & 10 & 6.1 & 20 & 12.1 & 3.64 \\
\hline 10 & E-book & 63 & 38.2 & 45 & 27.3 & 32 & 19.4 & 12 & 7.3 & 13 & 7.9 & 3.81 \\
\hline
\end{tabular}

Table 6 shows that the responses of female teachers to domain I "devices and applications used by the female teachers in teaching Math to the middle stage", are as follows: always achieved (3.6\%-48.5\%); often achieved (11.5\%-27.3\%); sometimes achieved (15.2\%-46.1\%); rarely achieved (3.0\%-20\%); and never achieved $(6.7 \%-33.3 \%)$.

The table shows that all standards achieved arithmetic means that achieved (2.07-4.07). In addition, (4) standards arithmetic means achieved (3.41-4.20) that are classified into the (often) available standards. A similar number achieved (2.61-3.40) that are classified into the (sometimes) available standards. Two standards achieved (1.812.60) that are classified into the (rarely) available standards. This indicates that most standards of the first domain obtained (often and rarely) because of the learners' awareness of the importance of employing these devices and applications in teaching math. They also had the required skills. While this result matched Murad (2014), it differed from Elzebyani (2007).

To answer the second question "to what extent ICT is employed in teaching Math from the perspective of female Math teachers of middle stage?", frequencies, percentage, and arithmetic means are used, as shown in Table 7. 
Table 7. Frequencies, percentage, and arithmetic mean of the participants' responses to "indicators of employing ICT in teaching Math to the middle stage" domain

\begin{tabular}{|c|c|c|c|c|c|c|c|c|c|c|c|c|}
\hline \multirow{2}{*}{ No. } & \multirow{2}{*}{ Item } & \multicolumn{2}{|c|}{ Always } & \multicolumn{2}{|c|}{ Often } & \multicolumn{2}{|c|}{ Sometimes } & \multicolumn{2}{|c|}{ Rarely } & \multicolumn{2}{|c|}{ Never } & \multirow{2}{*}{$\begin{array}{c}\text { Arithmetic } \\
\text { mean }\end{array}$} \\
\hline & & $\mathrm{T}$ & $\%$ & $\mathrm{~T}$ & $\%$ & $\mathrm{~T}$ & $\%$ & $\mathrm{~T}$ & $\%$ & $\mathrm{~T}$ & $\%$ & \\
\hline 1 & Teaching Planning of Math classes & 117 & 70.9 & 27 & 16.4 & 16 & 9.7 & 4 & 2.4 & 1 & .6 & 4.55 \\
\hline 2 & $\begin{array}{l}\text { Guiding the female students to use the Internet } \\
\text { for reading, research, and investigation }\end{array}$ & 83 & 50.3 & 42 & 25.5 & 35 & 21.2 & 4 & 2.4 & 1 & .6 & 4.22 \\
\hline 3 & $\begin{array}{l}\text { Supporting the female students with enrichment } \\
\text { and remedial activities }\end{array}$ & 54 & 32.7 & 50 & 30.3 & 52 & 31.5 & 7 & 4.2 & 2 & 1.2 & 3.89 \\
\hline 4 & $\begin{array}{l}\text { Encouraging the female students in Math class } \\
\text { to be able to use ICT tools }\end{array}$ & 59 & 35.8 & 43 & 26.1 & 46 & 27.9 & 12 & 7.3 & 5 & 3.0 & 3.84 \\
\hline 5 & $\begin{array}{l}\text { Guiding the abilities and developing the gifts of } \\
\text { female students }\end{array}$ & 74 & 44.8 & 50 & 30.3 & 28 & 17.0 & 11 & 6.7 & 2 & 1.2 & 4.11 \\
\hline 6 & $\begin{array}{l}\text { Diversity of the teaching and technological } \\
\text { treatments in Math class to consider individual } \\
\text { differences }\end{array}$ & 62 & 37.6 & 45 & 27.3 & 40 & 24.2 & 11 & 6.7 & 7 & 4.2 & 3.87 \\
\hline 7 & $\begin{array}{l}\text { Arithmetic treatments developments, finding } \\
\text { the outputs of processes, or verifying the results } \\
\text { of algorithms }\end{array}$ & 50 & 30.3 & 48 & 29.1 & 43 & 26.1 & 14 & 8.5 & 10 & 6.1 & 3.69 \\
\hline 8 & $\begin{array}{l}\text { Identifying and concluding the features of } \\
\text { geometric figures }\end{array}$ & 99 & 60.0 & 37 & 22.4 & 19 & 11.5 & 4 & 2.4 & 6 & 3.6 & 4.33 \\
\hline 9 & $\begin{array}{l}\text { Organization, representation, and summary of } \\
\text { the given data }\end{array}$ & 100 & 60.6 & 36 & 21.8 & 20 & 12.1 & 6 & 3.6 & 3 & 1.8 & 4.36 \\
\hline 10 & Building sports activities & 46 & 27.9 & 64 & 38.8 & 32 & 19.4 & 15 & 9.1 & 8 & 4.8 & 3.76 \\
\hline 11 & $\begin{array}{l}\text { Using the software of drawing the functions, } \\
\text { studying their features, and solving equations. }\end{array}$ & 45 & 27.3 & 42 & 25.5 & 45 & 27.3 & 20 & 12.1 & 13 & 7.9 & 3.52 \\
\hline 12 & $\begin{array}{l}\text { Using computational simulation to simulate the } \\
\text { lessons of maquettes and geometric } \\
\text { transformations }\end{array}$ & 36 & 21.8 & 43 & 26.1 & 43 & 26.1 & 17 & 10.3 & 26 & 15.8 & 3.28 \\
\hline 13 & $\begin{array}{l}\text { Activating individual learning via programmed } \\
\text { education or problem solving }\end{array}$ & 62 & 37.6 & 42 & 25.5 & 32 & 19.4 & 16 & 9.7 & 13 & 7.9 & 3.75 \\
\hline 14 & $\begin{array}{l}\text { Designing evaluative activities of different } \\
\text { levels }\end{array}$ & 49 & 29.7 & 54 & 32.7 & 35 & 21.2 & 18 & 10.9 & 9 & 5.5 & 3.70 \\
\hline 15 & $\begin{array}{l}\text { Measurement of learning motivation and the } \\
\text { attitude towards the continuity of education } \\
\text { among the female students }\end{array}$ & 53 & 32.1 & 40 & 24.2 & 47 & 28.5 & 16 & 9.7 & 9 & 5.5 & 3.68 \\
\hline 16 & Assessment of sports communication skills & 45 & 27.3 & 47 & 28.5 & 43 & 26.1 & 16 & 9.7 & 14 & 8.5 & 3.56 \\
\hline 17 & $\begin{array}{l}\text { Assessment of personality aspects among the } \\
\text { female students to foster strengths and treat } \\
\text { weakness }\end{array}$ & 75 & 45.5 & 48 & 29.1 & 27 & 16.4 & 10 & 6.1 & 5 & 3.0 & 4.08 \\
\hline 18 & $\begin{array}{l}\text { Evaluation of the cognitive, skill, and emotional } \\
\text { learning aspects of the female students in Math } \\
\text { class }\end{array}$ & 78 & 47.3 & 51 & 30.9 & 22 & 13.3 & 8 & 4.8 & 6 & 3.6 & 4.13 \\
\hline 19 & Supporting self-assessment in Math & 68 & 41.2 & 52 & 31.5 & 22 & 13.3 & 16 & 9.7 & 7 & 4.2 & 3.96 \\
\hline 20 & $\begin{array}{l}\text { Allowing the female students to electronically } \\
\text { design their achievement portfolios }\end{array}$ & 45 & 27.3 & 41 & 24.8 & 33 & 20.0 & 21 & 12.7 & 25 & 15.2 & 3.36 \\
\hline 21 & $\begin{array}{l}\text { Electronically design the achievement portfolio } \\
\text { of the female teacher }\end{array}$ & 59 & 35.8 & 32 & 19.4 & 37 & 22.4 & 15 & 9.1 & 22 & 13.3 & 3.55 \\
\hline 22 & $\begin{array}{l}\text { Electronic communication between the female } \\
\text { math teacher and female students via e-mail to } \\
\text { follow-up the constructive assessment. }\end{array}$ & 23 & 13.9 & 20 & 12.1 & 40 & 24.2 & 26 & 15.8 & 56 & 33.9 & 2.56 \\
\hline 23 & $\begin{array}{l}\text { Diagnosis of the difficulties that face the female } \\
\text { students in math learning }\end{array}$ & 61 & 37.0 & 54 & 32.7 & 35 & 21.2 & 9 & 5.5 & 6 & 3.6 & 3.94 \\
\hline 24 & Teaching performance development & 96 & 58.2 & 35 & 21.2 & 28 & 17.0 & 4 & 2.4 & 2 & 1.2 & 4.33 \\
\hline
\end{tabular}




\begin{tabular}{|c|c|c|c|c|c|c|c|c|c|c|c|c|}
\hline 25 & $\begin{array}{l}\text { Reviewing the modern trends in the programs } \\
\text { of math teaching and learning in symposia, } \\
\text { conferences, and seminars }\end{array}$ & 79 & 47.9 & 40 & 24.2 & 32 & 19.4 & 11 & 6.7 & 3 & 1.8 & 4.10 \\
\hline 26 & $\begin{array}{l}\text { Participation in the forums of Math teachers in } \\
\text { Saudi Arabia }\end{array}$ & 60 & 36.4 & 35 & 21.2 & 39 & 23.6 & 10 & 6.1 & 21 & 12.7 & 3.62 \\
\hline 27 & Building questions' banks & 38 & 23.0 & 51 & 30.9 & 40 & 24.2 & 18 & 10.9 & 18 & 10.9 & 3.44 \\
\hline 28 & Designing the electronic educational lessons & 52 & 31.5 & 46 & 27.9 & 40 & 24.2 & 14 & 8.5 & 13 & 7.9 & 3.67 \\
\hline 29 & Electronically communicate with the guardians & 20 & 12.1 & 17 & 10.3 & 45 & 27.3 & 18 & 10.9 & 65 & 39.4 & 2.45 \\
\hline 30 & Employing multimedia programs in teaching & 34 & 20.6 & 39 & 23.6 & 54 & 32.7 & 16 & 9.7 & 22 & 13.3 & 3.28 \\
\hline
\end{tabular}

Table 7 shows that the responses of female students to domain II "indicators of employing ICT in teaching Math to the middle stage", are as follows: always achieved (12.1\%-70.9\%); often achieved (10.3\%-38.8\%); sometimes achieved (9.7\%-32.7\%); rarely achieved (2.4\%-15.8\%); and never achieved (0.6\%-39.4\%).

The table shows that all standards achieved arithmetic means that achieved (2.45-4.55). In addition, (5) standards achieved arithmetic means of (4.21-5) that are classified into the (always) available standards. Besides, (20) standards achieved (3.41-4.20) that are classified into the (often) available standards. Three standards achieved (2.61-3.40) that are classified into the (sometimes) available standards. Two standards achieved arithmetic means of (1.81 - 2.60) that are classified into the (rarely) available standards. This indicates that most standards of domain II achieved (often) degree. This may happen because of the medium degree of using applications and devices in Math teaching reported by the result of the first question. In return, it was reflected on the employment of ICT in Math teaching, indicating the awareness of female teachers of their importance and the skills of using them. While this result matches (Elzahrany, 2005) and (Alrajeh \& Elzain, 2015), it differs from (Murad, 2014).

To answer the third question "what are the difficulties of employing ICT in teaching Math from the perspective of female Math teachers of middle stage?", frequencies, percentage, and arithmetic means are used, as shown in Table 8 .

Table 8. Frequencies, percentage, and arithmetic mean of the participants' responses to "the difficulties of employing ICT in teaching Math from the perspective of female Math teachers of middle stage?" domain

\begin{tabular}{|c|c|c|c|c|c|c|c|c|c|c|}
\hline \multirow[t]{2}{*}{ No. } & \multirow[t]{2}{*}{ Item } & \multicolumn{2}{|c|}{$\begin{array}{c}\text { Great } \\
\text { difficulty }\end{array}$} & \multicolumn{2}{|c|}{$\begin{array}{l}\text { Medium } \\
\text { difficulty }\end{array}$} & \multicolumn{2}{|c|}{$\begin{array}{c}\text { Slight } \\
\text { difficulty }\end{array}$} & \multicolumn{2}{|c|}{$\begin{array}{l}\text { No } \\
\text { difficulty }\end{array}$} & \multirow{2}{*}{$\begin{array}{l}\text { Arithmetic } \\
\text { mean }\end{array}$} \\
\hline & & $\mathrm{T}$ & $\%$ & $\mathrm{~T}$ & $\%$ & $\mathrm{~T}$ & $\%$ & $\mathrm{~T}$ & $\%$ & \\
\hline 1 & Shortage of computer devices in the school & 84 & 50.9 & 47 & 28.5 & 28 & 17.0 & 6 & 3.6 & 1.73 \\
\hline 2 & Bad or unavailable Internet service in the school & 108 & 65.5 & 32 & 19.4 & 22 & 13.3 & 3 & 1.8 & 1.52 \\
\hline 3 & Inadequate class time & 84 & 50.9 & 46 & 27.9 & 27 & 16.4 & 8 & 4.8 & 1.75 \\
\hline 4 & $\begin{array}{l}\text { A large number of female students in one } \\
\text { classroom }\end{array}$ & 101 & 61.2 & 39 & 23.6 & 21 & 12.7 & 4 & 2.4 & 1.56 \\
\hline 5 & $\begin{array}{l}\text { Shortage of good models of employing ICT in } \\
\text { teaching }\end{array}$ & 78 & 47.3 & 48 & 29.1 & 28 & 17.0 & 11 & 6.7 & 1.83 \\
\hline 6 & $\begin{array}{l}\text { Lack of the adequate technical support in the } \\
\text { school }\end{array}$ & 92 & 55.8 & 46 & 27.9 & 21 & 12.7 & 6 & 3.6 & 1.64 \\
\hline 7 & $\begin{array}{l}\text { Inappropriateness of the organization of classroom } \\
\text { environment }\end{array}$ & 94 & 57.0 & 41 & 24.8 & 23 & 13.9 & 7 & 4.2 & 1.65 \\
\hline 8 & $\begin{array}{l}\text { Shortage of competences that enable me } \\
\text { effectively adopt ICT in teaching. }\end{array}$ & 65 & 39.4 & 53 & 32.1 & 32 & 19.4 & 15 & 9.1 & 1.98 \\
\hline 9 & $\begin{array}{l}\text { Low learning motivation and desire among the } \\
\text { female students with the help of ICT }\end{array}$ & 52 & 31.5 & 59 & 35.8 & 41 & 24.8 & 13 & 7.9 & 2.09 \\
\hline 10 & $\begin{array}{l}\text { No cooperation of the learning centers with the } \\
\text { female teachers }\end{array}$ & 49 & 29.7 & 52 & 31.5 & 33 & 20.0 & 31 & 18.8 & 2.28 \\
\hline 11 & $\begin{array}{l}\text { Difficulty of dealing with English as the language } \\
\text { of the Internet }\end{array}$ & 48 & 29.1 & 56 & 33.9 & 42 & 25.5 & 19 & 11.5 & 2.19 \\
\hline 12 & Weak training on employing ICT in teaching & 57 & 34.5 & 57 & 34.5 & 33 & 20.0 & 18 & 10.9 & 2.07 \\
\hline
\end{tabular}

Table 8 shows that the female students' responses to domain III "the difficulties of employing ICT in teaching 
Math from the perspective of female Math teachers of middle stage" were as follows: Great difficulty achieved (29.1\%-65.5\%); medium difficulty achieved (19.4\%-35.8\%); low difficulty achieved (12.7\%-25.5\%); and no difficulty achieved (1.8\%-18.8\%).

Table 8 shows that all standards had arithmetic means of (1.52-2.28). While 6 standards achieved arithmetic means of (1-1.75) that are classified into (great difficulty), a similar group achieved arithmetic means of (1.76-2.50) that are classified into (medium difficulty). This indicates that all the standards of domain III were available with (great and medium difficulties). This is interpreted as the difficulties that had a great difficulty were related to administrative and organizational factors not directly related to make decisions or actions on the part of the concerned parties (Elzahrany, 2005). This result matches Elzahrany (2005), Elzebyani (2007), Alqurashy (2007), A. Elomary and K. Elomary (2008) and Murad (2014).

\subsection{Testing Hypotheses Validity}

Testing the validity of the first hypothesis:

To test the validity of the first hypothesis, arithmetic means, standard deviations, and ANOVA analysis, as shown in Table 9. Table 10 ANOVA analysis of the responses of female Math teachers of middle stage to the questionnaire of the reality and difficulties of employing ICT in total teaching and its domains according to academic qualification.

Table 9. Arithmetic means and standard deviations of the responses of female Math teachers of middle stage to the questionnaire of the reality and difficulties of employing ICT in teaching and its domains according to academic qualification

\begin{tabular}{|c|c|c|c|c|}
\hline Domain & Qualification & Size of the sample & Arithmetic mean & Standard deviation \\
\hline \multirow{7}{*}{ Domain I } & General secondary stage & 1 & 32.00 & . \\
\hline & Diploma & 3 & 41.67 & 7.234 \\
\hline & Bachelor & 148 & 31.42 & 8.105 \\
\hline & Higher Diploma & 3 & 28.00 & 3.606 \\
\hline & Master & 9 & 28.00 & 8.775 \\
\hline & Ph.D. & 1 & 36.00 & . \\
\hline & Total & 165 & 31.39 & 8.145 \\
\hline \multirow{7}{*}{ Domain II: } & General secondary stage & 1 & 128.00 & . \\
\hline & Diploma & 3 & 128.67 & 19.140 \\
\hline & Bachelor & 148 & 113.32 & 21.896 \\
\hline & Higher Diploma & 3 & 91.33 & 40.377 \\
\hline & Master & 9 & 101.56 & 27.148 \\
\hline & Ph.D. & 1 & 105.00 & . \\
\hline & Total & 165 & 112.59 & 22.627 \\
\hline \multirow{7}{*}{ Domain III: } & General secondary stage & 1 & 24.00 & . \\
\hline & Diploma & 3 & 15.00 & 3.000 \\
\hline & Bachelor & 148 & 22.55 & 7.603 \\
\hline & Higher Diploma & 3 & 22.67 & 7.638 \\
\hline & Master & 9 & 20.11 & 4.106 \\
\hline & Ph.D. & 1 & 25.00 & . \\
\hline & Total & 165 & 22.31 & 7.404 \\
\hline \multirow{7}{*}{ Total marks } & General secondary stage & 1 & 184.00 & . \\
\hline & Diploma & 3 & 185.33 & 28.449 \\
\hline & Bachelor & 148 & 167.29 & 30.401 \\
\hline & Higher Diploma & 3 & 142.00 & 51.098 \\
\hline & Master & 9 & 149.67 & 35.927 \\
\hline & Ph.D. & 1 & 166.00 & . \\
\hline & Total & 165 & 166.29 & 31.121 \\
\hline
\end{tabular}


Table 10. ANOVA analysis of the responses of female Math teachers of middle stage to the questionnaire of the reality and difficulties of employing ICT in total teaching and its domains according to academic qualification

\begin{tabular}{|c|c|c|c|c|c|c|}
\hline Domain & Source of variance & Total of squares & Freedom degrees & Statistical Means of squares & "F" value & Significance level \\
\hline \multirow{3}{*}{ Domain I } & Between groups & 476.482 & 5 & 95.296 & & \\
\hline & Within groups & 10402.694 & 159 & 65.426 & 1.457 & .207 \\
\hline & Total & 10879.176 & 164 & & & \\
\hline \multirow{3}{*}{ Domain II: } & Between groups & 3600.164 & 5 & 720.033 & & \\
\hline & Within groups & 80365.630 & 159 & 505.444 & 1.425 & .218 \\
\hline & Total & 83965.794 & 164 & & & \\
\hline \multirow{3}{*}{ Domain III: } & Between groups & 223.113 & 5 & 44.623 & & \\
\hline & Within groups & 8766.123 & 159 & 55.133 & .809 & .545 \\
\hline & Total & 8989.236 & 164 & & & \\
\hline \multirow{3}{*}{ Total marks } & Between groups & 5806.863 & 5 & 1161.373 & & \\
\hline & Within groups & 153027.173 & 159 & 962.435 & 1.207 & .308 \\
\hline & Total & 158834.036 & 164 & & & \\
\hline
\end{tabular}

Table 10 shows that " $F$-value $=1.457,1.425,0.809$, and 1.207 regarding academic qualification on the three domains and the questionnaire in total. It is statistically insignificant at the level of $(\alpha \leq 0.05)$. Thus, the first statistical hypothesis that states that "there were no statistically significant differences at the level of $(\alpha \leq 00.05)$ between the means of responses of the participants due to scientific qualification" is accepted. This affirms that there is no discrepancy between the female teachers' responses due to academic qualification as they all teach in the same schools and they all receive training courses to employ ICT in teaching Math. While this result agrees with Bakhiet and Alhasan (2013), it differs from Alqurashy (2007) and Alqahtany (2013).

Testing the validity of the second hypothesis:

To test the validity of the second hypothesis, arithmetic means, standard deviations, and ANOVA analysis, as shown in Table 11. Table 12 ANOVA analysis of the responses of female Math teachers of middle stage to the questionnaire of the reality and difficulties of employing ICT in total teaching and its domains according to specialization.

Table 11, Arithmetic means and standard deviations of the responses of female Math teachers of middle stage to the questionnaire of the reality and difficulties of employing ICT in total teaching and its domains according to specialization

\begin{tabular}{lcccc}
\hline Domain & Specialization & Size of the sample & Arithmetic mean & Standard deviation \\
\hline \multirow{4}{*}{ Domain I } & Math & 152 & 31.35 & 8.183 \\
& Science \& Math & 9 & 29.44 & 8.110 \\
& Other & 4 & 37.25 & 4.856 \\
& Total & 165 & 31.39 & 8.145 \\
& Math & 152 & 112.22 & 23.205 \\
Domain II: & Science \& Math & 9 & 112.33 & 14.353 \\
& Other & 4 & 127.25 & 6.500 \\
& Total & 165 & 112.59 & 22.627 \\
& Math & 152 & 22.24 & 7.387 \\
Domain III: & Science \& Math & 9 & 25.00 & 8.382 \\
& Other & 4 & 19.00 & 5.099 \\
& Total & 165 & 22.31 & 7.404 \\
& Math & 152 & 165.81 & 31.841 \\
& Sotal marks & 9 & 166.78 & 22.135 \\
& Ocience \& Math & 4 & 183.50 & 14.201 \\
& Other & 165 & 166.29 & 31.121 \\
\hline
\end{tabular}


Table 12. ANOVA analysis of the responses of female Math teachers of middle stage to the questionnaire of the reality and difficulties of employing ICT in total teaching and its domains according to specialization

\begin{tabular}{|c|c|c|c|c|c|c|}
\hline Domain & Source of variance & Total of squares & Freedom degrees & Statistical Means of squares & "F" value & Significance level \\
\hline \multirow{3}{*}{ Domain I } & Between groups & 171.684 & 2 & 85.842 & & \\
\hline & Within groups & 10707.492 & 162 & 66.096 & 1.299 & .276 \\
\hline & Total & 10879.176 & 164 & & & \\
\hline \multirow{3}{*}{ Domain II: } & Between groups & 880.649 & 2 & 440.325 & & \\
\hline & Within groups & 83085.145 & 162 & 512.871 & .859 & .426 \\
\hline & Total & 83965.794 & 164 & & & \\
\hline \multirow{3}{*}{ Domain III: } & Between groups & 109.763 & 2 & 54.881 & & \\
\hline & Within groups & 8879.474 & 162 & 54.812 & 1.001 & .370 \\
\hline & Total & 8989.236 & 164 & & & \\
\hline \multirow{3}{*}{ Total marks } & Between groups & 1222.014 & 2 & 611.007 & & \\
\hline & Within groups & 157612.023 & 162 & 972.914 & .628 & .535 \\
\hline & Total & 158834.036 & 164 & & & \\
\hline
\end{tabular}

Table 12 shows that " $F$-value $=1.299,0.859,1.001$, and 0.628 regarding specialization on the three domains and the questionnaire in total. It is statistically insignificant at the level of $(\alpha \leq 0.05)$. Thus, the second statistical hypothesis that states that "there were no statistically significant differences at the level of $(\alpha \leq 00.05)$ between the means of responses of the participants due to specialization." is accepted. This affirms that there is no discrepancy between the female teachers' responses due to specialization as they all teach in the same schools and they all receive training courses to employ ICT in teaching Math. Additionally, most of the participants hold the Bachelor degree in Math. Accordingly, they have the same type of preparation, awareness, and skills. To the author's knowledge, there is not a single study that investigated the differences of the sample due to specializations, as conducted in the study.

Testing the validity of the third hypothesis:

To test the validity of the third hypothesis, arithmetic means, standard deviations, and ANOVA analysis, as shown in Table 13. Table 14 ANOVA analysis of the responses of female Math teachers of middle stage to the questionnaire of the reality and difficulties of employing ICT in total teaching and its domains according to years of experience.

Table 13. Arithmetic means and standard deviations of the responses of female Math teachers of middle stage to the questionnaire of the reality and difficulties of employing ICT in total teaching and its domains according to years of experience

\begin{tabular}{lcccc}
\hline Domain & Years of experience & Size of the sample & Arithmetic mean & Standard deviation \\
\hline \multirow{7}{*}{ Domain I } & Less than 5 years & 15 & 33.47 & 5.462 \\
& From 5 to 10 years & 45 & 33.58 & 7.563 \\
& From 10 to 15 years & 25 & 30.28 & 8.877 \\
& From 15 to 20 years & 56 & 30.89 & 8.022 \\
& More than 20 years & 24 & 28.29 & 9.229 \\
& Total & 165 & 31.39 & 8.145 \\
& Less than 5 years & 15 & 119.33 & 15.305 \\
& From 5 to 10 years & 45 & 119.60 & 20.614 \\
Domain II: & From 10 to 15 years & 25 & 110.64 & 22.331 \\
& From 15 to 20 years & 56 & 108.04 & 23.353 \\
& More than 20 years & 24 & 107.92 & 25.835 \\
& Total & 165 & 112.59 & 22.627 \\
& Less than 5 years & 15 & 25.33 & 10.168 \\
& From 5 to 10 years & 45 & 22.33 & 6.987 \\
& From 10 to 15 years & 25 & 22.48 & 6.995 \\
Domain III: & From 15 to 20 years & 56 & 21.29 & 7.436 \\
& More than 20 years & 24 & 22.58 & 6.527 \\
& Total & 165 & 22.31 & 7.404 \\
& Less than 5 years & 15 & 178.13 & 24.721 \\
\hline
\end{tabular}




\begin{tabular}{cccc}
\hline From 5 to 10 years & 45 & 175.51 & 26.181 \\
From 10 to 15 years & 25 & 163.40 & 32.436 \\
From 15 to 20 years & 56 & 160.21 & 31.329 \\
More than 20 years & 24 & 158.79 & 36.909 \\
Total & 165 & 166.29 & 31.121 \\
\hline
\end{tabular}

Table 14. ANOVA analysis of the responses of female Math teachers of middle stage to the questionnaire of the reality and difficulties of employing ICT in total teaching and its domains according to years of experience

\begin{tabular}{|c|c|c|c|c|c|c|}
\hline Domain & Source of variance & Total of squares & Freedom degrees & Statistical Means of squares & "F" value & Significance level \\
\hline \multirow{3}{*}{ Domain I } & Between groups & 555.109 & 4 & 138.777 & & \\
\hline & Within groups & 10324.067 & 160 & 64.525 & 2.151 & .077 \\
\hline & Total & 10879.176 & 164 & & & \\
\hline \multirow{3}{*}{ Domain II: } & Between groups & 4674.139 & 4 & 1168.535 & & \\
\hline & Within groups & 79291.655 & 160 & 495.573 & 2.358 & .056 \\
\hline & Total & 83965.794 & 164 & & & \\
\hline \multirow{3}{*}{ Domain III: } & Between groups & 198.401 & 4 & 49.600 & & \\
\hline & Within groups & 8790.835 & 160 & 54.943 & .903 & .464 \\
\hline & Total & 8989.236 & 164 & & & \\
\hline \multirow{3}{*}{ Total marks } & Between groups & 9555.672 & 4 & 2388.918 & & \\
\hline & Within groups & 149278.365 & 160 & 932.990 & 2.560 & .041 \\
\hline & Total & 158834.036 & 164 & & & \\
\hline
\end{tabular}

Table 14 shows that "F-value $=2.151,2.358,0.903$, and 2.560 regarding years of experience on the three domains and the questionnaire in total. It is statistically insignificant at the level of $(\alpha \leq 0.05)$. Thus, the third statistical hypothesis that states that "there were no statistically significant differences at the level of $(\alpha \leq 0.05)$ between the means of responses of the participants due to years of experience." is accepted. At the same time, it was refused at the level of the total questionnaire. This affirms that there is no discrepancy between the responses of female teachers due to years of experience on each domain. Howevere, there is discrepancy at the level of the total questionnaire.

To define the source of difference, Turkey test was used. Table () Results of Turkey test of the resources of differences between the means of female Math teachers of middle stage's responses to the total questionnaire.

Table 15. Turkey test of the resources of differences between the means of female Math teachers of middle stage's responses to the total questionnaire according to years of experience

\begin{tabular}{cccc}
\hline (I) Years of experience & (J) Years of experience & Differences between means (I-J) & Significance level \\
\hline \multirow{4}{*}{ Less than 5 years } & From 5 to 10 years & 2.622 & .774 \\
& From 10 to 15 years & 14.733 & .142 \\
& From 15 to 20 years & $17.919^{*}$ & .045 \\
& More than 20 years & 19.342 & .056 \\
& Less than 5 years & $-2.622-$ & .774 \\
From 5 to 10 years & From 10 to 15 years & 12.111 & .114 \\
& From 15 to 20 years & $15.297^{*}$ & .013 \\
& More than 20 years & $16.719^{*}$ & .032 \\
& Less than 5 years & $-14.733-$ & .142 \\
From 10 to 15 years & From 5 to 10 years & $-12.111-$ & .114 \\
& From 15 to 20 years & 3.186 & .665 \\
& More than 20 years & 4.608 & .598 \\
& Less than 5 years & $-17.919-^{*}$ & .045 \\
From 15 to 20 years & From 5 to 10 years & $-15.297-{ }^{*}$ & .013 \\
& From 10 to 15 years & $-3.186-$ & .665 \\
& More than 20 years & 1.423 & .849 \\
& Less than 5 years & $-19.342-$ & .056 \\
More than 20 years & From 5 to 10 years & $-16.719-{ }^{*}$ & .032 \\
& From 10 to 15 years & $-4.608-$ & .598 \\
\hline
\end{tabular}


Table 15 shows that the source of differences between the means of female teachers' responses to years of experience on 1-5 years and 15-20 years favored 1-5 years. In addition, the source of differences of the female teachers' responses on years of experience on 5-10 years, 15-20 years, and more than 20 years favored 5-10 years. This may be attributed to the fact that those with less experience were fresh ones that they were trained on convoying modern technology. This was positively reflected on their awareness and the skills of employing ICT in Math teaching. While this result agrees with Alqurashy (2007), Alqahtany (2015), and Olimat (2014), it differs from Elzebyani (2007) and Alrajeh and Elzain (2015).

\section{Recommendations and Suggestions}

1) Defining the training needs of teachers in ICT and considering their opinions and suggestions when designing and implementing the programs and training workshops (Albaqaly, 2011).

2) Providing help and support to teachers to overcome the difficulties that limit their ability of using and effectively employing ICT in education (Albaqaly, 2011).

3) Establishing a technological infrastructure in schools to help teachers merge ICT with the skills of the classroom teaching situation as it contributes to increasing its employment in teaching (Elomary \& Elomary, 2008).

4) Developing Math curricula in all stages of public education according to the employment of ICT.

5) Conducting further studies that tackle new variables, e.g. the attitudes of teachers towards employing ICT in teaching.

6) Conducting further studies that provide a proposal of employing ICT in Math teaching.

7) Reconducting the current study on the female teachers of the primary and secondary teachers and female educational supervisors.

8) Conducting studies on the effectiveness of employing ICT in developing dependent variables including achievement, thinking and its different fields, retaining learning, attitude, self-concept, and learning motivation.

\section{References}

Abuzaina, F. K., \& Ababna, A. Y. (2007). Curricula of teaching Math to the first grades. Amman: Dar Almasera.

Albaqaly, A. A. (2011). The reality of using information and communication technology in the classroom teaching in Bahrain: A field study in the public schools in Bahrain. Journal of the Faculty of Arts-Benha University, Egypt, 26.

Alhamran, M. (2006). A field study of the reality of information and communication technology in the exploratory schools in Jordan (Unpublished Ph.D. dissertation). The University of Jordan.

Aljarah, A. A., \& Elajloni, K.I. (2012). The degree of using information and communication technology by kindergarten female teachers in Oman and its obstacles. Journal of Educational \& Psychological Sciences-Bahrain, 13(1).

Alqahtany, A. A. (2013). The reality of exploiting technological innovations in teaching the Mathematics of the developed curricula from the perspective of teachers and educational supervisors in Tabuk educational directorate. The International Specialized Educational Journal, 2(5).

Alqurashy, W. S. (2007). The reality of using the computer, world wide web and Internet in teaching Mathematics to the first middle grade in Al-Taief (Unpublished MA. thesis). Umm Al-Qura University.

Alrajeh, N. M., \& Elzain, H. B. (2015). The reality of digital technologies in supporting the professional development of female Math teachers. Arab Studies in Education and Psychology-Saudi, 64.

Arab Bureau of Education for the Gulf states (n.d.). Criteria of education technology among students, teachers, and principals.

Ayas, C. (2006). An examination of the relationship between the Integration of technology into social studies and constructivist pedagogies. The Turkish Online Journal of Educational Technology-TOJET, 5(1).

Azazy, F. M. (2010). A proposal to activate the role of general secondary education using information and technology education. Proceedings of the $5^{\text {th }}$ International Conference (The Future of Reforming Arab 
Education to Knowledge Community: Experience, Criteria and Perspectives), Cairo.

Bakhiet, S. F., \& Alhasan, Z. A. (2013). The reality of information and communication technology in the schools of the gifted. Proceedings from the $10^{\text {th }}$ Arab Scientific Conference on Taking Care of the Gifted and High Achievers "Standards and Indicators of Excellence: Educational Reformation and Taking Care of the Gifted and High Achievers", The Arab Council of the Gifted and High Achievers, Jordan.

Bate, F. (2010). A bridge too far? explaining beginning teachers' use of ICT in Australian schools, Australasian Journal of Educational Technology, 26(7).

Bebell, D., Russell, M., \& O’Dwyer, L. (2004). Measuring teachers' technology uses: Why multiple measures are more revealing. Journal of Research on Technology in Education, 37(1). https://doi.org/10.1080/15391523.2004.10782425

Bindu, C.N. (2017). Attitude towards, and awareness of using ICT in Classrooms: A case of expatriate Indian teachers in UAE. Journal of Education and Practice, 8(1).

Buabeng-Andoh, C. (2012). Factors influencing teachers' adoption and integration of information and communication technology into teaching: A review of the literature. International Journal of Education and Development Using Information and Communication Technology, 8(1).

Casey, J. (2008). Students “power down” for school: Technology left behind. Reading Today, (July).

Copriad, J. (2014). Self- motivation as a mediator for teachers' readiness in applying ICT in teaching and learning. The Turkish Online Journal of Educational Technology, 13(4).

Dakich, E., Vale, C., Thalathoti, V. \& Cherednichenko, B. (2008). Factors influencing teachers' ICT literacy: A snapshot from Australia. In J. Luca, \& E. Weippl (Eds.), Proceedings of Edmedia: World Conference on Educational Media and Technology 2008. Association for the Advancement of Computing in Education (AACE). Retrieved From https://Www.Learntechlib.Org/Noaccess/28895

Daniel, J. (2002). Information and communication technology in education. UNESCO.

Elhemealy, Y. J. (2005). The reality of using the computer in the public sector in Saudi Arabia "obstacles \& solutions". Riyadh: Public Administration Institute.

Eljahemy, A. (2010). Evaluation of the (developed) book of Fiqh for the third secondary stage according to the contemporary criteria of school book. Message of the Arabian Gulf, 31(116).

Elnaeby, S. A. (2010). The reality and obstacles of using information and communication technology in a sample of the internal area school teachers in Oman. Journal of Educational \& Psychological Sciences, 11(3).

Elomary, A., \& Elomary, K. (2008). The reality of adopting information and communication technology in the classroom educational situation skills in the three primary grads in Arbad from the perspective of teachers. Journal of University for Research \& Scientific Studies (Arts \& Humantities Series), Syria, 30(1).

Elomary, R., \& Anaqra, F. (2011). The effectiveness of e-learning in the exploratory schools from the perspective of their principals in Jordan. Culture \& Development-Egypt, 11(45).

Elrawabda, M. A. (2002). The impact of using the educational packages in teaching the recitation of the Holy Qur'an (Unpublished MA. thesis). Al Albayt University.

Elsalamey, A. A. (2002). Information technology (2nd ed.). Amman: Dar Almanahej for Publishing \& Distribution.

Elzahrany, A.A. (2005). The reality of using the computer and Internet in teaching Mathematics to the secondary stage from the perspective of teachers and educational supervisors (Unpublished MA. thesis). Umm Al-Qura University.

Elzayd, A.M. (1990). Education in Saudi Arabia: A different model (4th ed.). Jeddah: Saudi Publishing House for Publishing and Distribution.

Elzebyani, A. A. (2007). The reality of contemporary technologies in teaching mathematics to the middle stage from the perspective of teachers (Unpublished MA. thesis). Umm Al-Qura University.

Fadl, A. M., \& Elrewy, Y. H. (2003). The reality of information and communication technology in the Yemeni Universities. Arab Forum on International Standards for Universities, The Arab Administrative Development Organization, Yemen.

Gebremedhin, M. A., \& Fenta, A. A. (2015). Assessing teachers' perception on integrating ICT in 
teaching-learning process: The case of Adwa College. Journal of Education and Practice, 6(4).

Hamdy, N. (1998). The degree of accepting the future roles by a sample of secondary stage students and teachers in the schools of Jordan as proposed by information technology. Studies- Educational Sciences, 25(2).

Hismanoglu, M. (2012). Prospective EFL teachers' perceptions of ICT integration: A study of distance higher education in Turkey. Educational Technology \& Society, 15(1).

Ismael, A. M. (2003). The role of e-learning technique in accomplishing the objectives of open education. In the Seminar of e-learning, King Faisal Schools, Riyadh, KSA.

Jamiu, F. O. (2016). Enhancing Arabic and Islamic studies education in Yorubaland through innovation and technology. In the $2^{\text {nd }}$ Interdisciplinary Conference Of TASUED-UCC 2016, 22 ${ }^{\text {nd }}-25^{\text {th }}$ August 2016 At Tai Solarin University of Education, Nigeria.

Khazaleh, T., \& Jawarneh, T. (2006). Barriers to effective information technology integration in Jordanian schools as perceived by in- service teachers. Jordan Journal of Educational Sciences, 2(4).

Konca, A. S., Ozel, E., \& Zelyurt, H. (2016). Attitudes of preschool teachers towards using information and communication technologies (ICT). International Journal of Research in Education and Science (IJRES), 2(1).

Murad, A. S. (2014). The reality and obstacles of using information and communication technology in teaching among the teachers of Shoubak schools, Jourdan. A l-Balqa Journal of Research and Studies, 17(1).

Naddaf, S. F. (2002). The reality of using the computer and the Internet in the private secondary schools in Jordan from the perspective of teachers (Unpublished MA. thesis). Yarmouk University.

Najy, M. (2001). Using information technology in the health field: An experience from Development of Education Resources Center. Arabia 3000- Syria, 2(2). Retrieved from http://www.mohyssin.com/forum/showthread.php?t=4640

Narinasamy, I., \& Mamat, W. H. (2013). Utilization of ICT by moral education teachers. The Malaysian Online Journal of Educational Technology, 1(4).

Obidat, Z., Adas, A., \& Abdulhaq, K. (1984). Scientific research: Concept, tools and methods. Amman: Dar Alfekr.

Olimat, A. (2014). The reality of using technological innovations by Science teachers in Mafraq governorate. AlManarah, 20(1b).

Statistical Information Center (1982). Chapters in the history of education in Saudi Arabia: Middle education in Saudi Arabia. Retrieved from http://www.kingkhalid.org.sa/Gallery/Text/ViewBooks.aspx?View=Tree\& cntrlId $=2 \&$ NodeID $=3 \&$ PageNo=1\&BookID $=141$ \&pageID $=2 \# 3$

Tella, A., Tella, A., O., Toyobo, A. L., \& Adeyinka, A.A. (2007). An assessment of secondary school teachers uses of ICT's: Implications for further development of ICT's use in Nigerian secondary schools. The Turkish Online Journal of Educational Technology-TOJET, 6(3).

Tezci, E. (2011). Turkish primary school teachers' perceptions of school culture regarding ICT integration. Education Tech Research Dev, 59. https://doi.org/10.1007/s11423-011-9205-6

\section{Copyrights}

Copyright for this article is retained by the author(s), with first publication rights granted to the journal.

This is an open-access article distributed under the terms and conditions of the Creative Commons Attribution license (http://creativecommons.org/licenses/by/4.0/). 